\title{
Teoría y práctica de las metodologías participativas. Análisis de su utilización para la elaboración de agendas de desarrollo territorial en Uruguay
}

\section{Theory and practice of participatory methodologies. Analysis of its use for the elaboration of territorial development agendas in Uruguay}

\section{Resumen}

El artículo analiza los cambios a nivel teórico-epistemológico en las ciencias sociales y su vinculación con los diseños de metodologías participativas. Se argumenta que las metodologías participativas se alimentan originalmente del pensamiento crítico, pero con el paso de los años van tomando elementos también del pensamiento complejo. Se realiza una caracterización de estas metodologías mostrando algunos elementos comunes dentro de la diversidad de variantes que emergieron a partir de la década del setenta del siglo pasado. Finalmente, se presenta un caso de aplicación de metodologías participativas para la construcción de agendas de desarrollo territorial en los municipios uruguayos. El análisis del caso permite ver la potencialidad de las herramientas que planifican con metodologías participativas, al tiempo que deja en evidencia ciertas limitaciones que se derivan de la adaptación de estos diseños a las reglas de los espacios institucionalizados.

Palabras clave: metodologías participativas; planificación; desarrollo territorial.

\begin{abstract}
The article analyzes the changes at the theoretical-epistemological level in the social sciences and their link with participatory methodologies designs. It is argued that participatory methodologies are originally based on critical thinking but over the years they are also taking elements of complex thinking. A characterization of these methodologies is carried out showing some common elements within the diversity of variants that emerged from the seventies of the last century. Finally, there is a case of applying participatory methodologies for the construction of territorial development agendas in Uruguayan municipalities. The analysis of the case allows to see the potentiality of the tools that use
\end{abstract}

\footnotetext{
${ }^{1}$ Doctor en Estudios Sociales de América Latina (UNC). Docente de la Universidad de la República, Sede Salto (Uruguay). Correo electrónico: marianodoc01@unorte.edu.uy.
} 
participatory methodologies while leaving in evidence certain limitations that derive the adaptation of these designs to the rules of the institutionalized spaces.

Keywords: participatory methodologies, planning, territorial development.

\section{Introducción}

Desde las últimas décadas del siglo pasado comienzan a emerger enfoques alternativos para el desarrollo de investigaciones sociales, en donde la ciencia no asume un papel neutro frente a la realidad y se reconceptualiza la relación entre investigadores e investigados, pasando estos últimos a asumir un papel activo en el proceso de generación de conocimiento y la búsqueda de estrategias superadoras. Son varias las vertientes, a las que en su conjunto se puede denominar como metodologías participativas (Villasante, 2015), y se han ido influyendo de manera recíproca a lo largo de estas décadas, así como han ido complejizando el aparato teórico del que se nutren.

A continuación, se hace una caracterización del pensamiento crítico y el pensamiento complejo como dos perspectivas que en la actualidad aparecen dando fundamento a estos enfoques. Luego se presentan los orígenes, los principios básicos y las características de los diseños participativos y, finalmente, un caso práctico en donde se adapta la metodología de la sociopraxis para construir agendas de desarrollo territorial en la órbita de los gobiernos locales de Uruguay.

\section{El cambio de perspectivas teóricas-epistemológicas}

\subsection{El pensamiento crítico}

Las metodologías participativas de investigación social surgen como correlato de las transformaciones que las ciencias sociales fueron sufriendo a nivel teórico y epistemológico a lo largo del siglo XX, sobre todo a partir de los aportes de la Escuela Crítica de Frankfurt con Horkheimer, Adorno y Habermas, entre otros. Es decir, la conformación de un nuevo modelo epistémico que se presenta como alternativo a los paradigmas positivistas e interpretativos (Sánchez Santamaría, 2013) impulsó, fundamentalmente, a partir de la década del setenta, la construcción de nuevos procedimientos de investigación ajustados a los principios del paradigma.

El paradigma crítico pretende superar el reduccionismo del positivismo y a la vez superar el conservadurismo del paradigma interpretativo, al que se acusa de no cuestionar a través de la investigación el statu quo de la sociedad. De esta manera, se admite la posibilidad de una ciencia social que no sea ni puramente empírica ni solo interpretativa, y sobre todo que ofrezca aportes para el cambio social desde el interior de las propias comunidades. Este paradigma introduce la ideología de forma explícita, así como la autorreflexión crítica en los 
procesos del conocimiento. Su finalidad es la transformación de la estructura de las relaciones sociales y dar respuesta a determinados problemas generados por estas, partiendo de la acción-reflexión de los integrantes de la comunidad (Melero, 2011).

Para Popkewitz (1988), las principales características del paradigma podrían resumirse en estos puntos:

(a) conocer y comprender la realidad como praxis; (b) unir teoría y práctica, integrando conocimiento, acción y valores; (c) orientar el conocimiento hacia la emancipación y liberación del ser humano; y (d) proponer la integración de todos los participantes, incluyendo al investigador, en procesos de autorreflexión y de toma de decisiones consensuadas, las cuales se asumen de manera corresponsable. (Alvarado y García, 2008: 190)

Por su parte, Habermas (1994) señala que el interés fundamental de la especie humana es el interés por la racionalidad. El interés más puro por la razón se expresa en tres intereses constitutivos del conocimiento: técnico (basado en el dominio de la naturaleza), práctico (orientado al entendimiento de las personas) y emancipador (busca la liberación y autonomía del individuo). Estos constituyen los tres tipos de ciencia mediante los que se genera y organiza el saber de nuestra sociedad. Estos tres enfoques son: empírico-analítico, histórico-hermenéutico y crítico. Entonces, para Habermas, el saber es el resultado de la actividad humana motivada por necesidades humanas e intereses. Las ciencias críticas de la sociedad sirven al interés emancipatorio, el cual está ligado a una forma de acción que es la autorreflexión (como el interés técnico lo estaba a la acción instrumental y el práctico a la comunicativa).

De esta forma, la ciencia social crítica apunta a ofrecer al individuo un instrumento de concientización sobre cómo sus objetivos y propósitos pueden haber sido distorsionados o reprimidos y de qué forma pueden buscar sus metas verdaderas (Alvarado y García, 2008).

Por su parte, en Latinoamérica también se produjo teoría crítica a través de autores como Paulo Freire, Orlando Fals Borda, Camilo Torres Restrepo y Aníbal Quijano, entre otros tantos. Ellos establecieron un diálogo con los autores críticos europeos tomando algunos de sus elementos, pero incorporando un debate con los supuestos coloniales y eurocéntricos del conocimiento de y sobre el continente (Fals Borda, 1991). Entonces, aparecen críticas al pensamiento eurocéntrico, incluso el de la propia teoría crítica, y un cuestionamiento a la modernidad excluyente. Así, la descolonialidad del saber será un elemento clave de las versiones latinoamericanas del pensamiento crítico y estará presente en las metodologías participativas entendidas, entre otras cosas, como una poderosa herramienta para el logro de este fin.

En síntesis, el paradigma crítico plantea una unidad dialéctica entre lo teórico y lo práctico, y de esta forma se sientan las bases para una investigación participativa que luego, 
con el paso de los años, se irá alimentando de otras bases teóricas y epistemológicas como las teorías de sistemas y el enfoque de la complejidad (Noboa y Suárez, 2018).

\subsection{El pensamiento complejo}

En un sentido estricto, no se trata de una teoría, sino de un conjunto de aportaciones sistémicas desde diferentes áreas del saber que comparten algunos elementos pero que no se han constituido en un cuerpo integrado de conocimiento. La idea de complejidad remite a la noción de interconexión, lo cual lleva a la noción de que la comprensión del mundo desde una perspectiva compleja debe concebirse como una entidad en donde todo se encuentra entrelazado. A su vez, el pensamiento complejo se basa en algunos conceptos centrales como: autoorganización, incertidumbre, no linealidad, reflexividad e interdisciplina (Noboa, 2019).

A lo largo del siglo $\mathrm{XX}$, sobre todo en la segunda mitad, ha habido diferentes aportaciones desde múltiples disciplinas que contribuyen a pensar el mundo (natural y social) de manera compleja y van dando cuerpo a la cosmovisión. En ese sentido, uno de los aportes clave vino de la mano de llya Prigogine, quien recibe en 1977 el premio Nobel de Química y con ello, entre otras cosas, eleva el status de una serie de conceptos que se venían desarrollando desde disciplinas como la biología, la psicología, la matemática, la antropología, la química, la filosofía, entre otras, y que suponen una nueva alianza entre el hombre y la naturaleza, y una ruptura con los axiomas clásicos de la ciencia (Solana, 1987).

Prigogine, que recupera el principio de incertidumbre de Heisenberg, se apoya en la idea de procesos irreversibles, en la organización a partir del caos, alejándose de esta forma de la ciencia newtoniana de las leyes inmutables. Una de las ideas centrales es que las estructuras disipativas de la materia y de la energía no se destruyen, sino que se recrean y se transforman de forma autónoma en nuevos sistemas (Noboa, 2019). De esta forma se privilegia la idea de autoorganización (tanto en el mundo vivo como inanimado), el azar y la no-linealidad, aspectos que habían sido ignorados por el pensamiento científico moderno.

En las ciencias sociales han sido clave los aportes de Edgar Morin (2007), quien invita a pensar la realidad social a partir de la idea de sistemas complejos. Para el autor, la idea de organización es fundamental para comprender la realidad desde una perspectiva compleja. A partir de ella, propone pasar de la idea de objeto esencial a la noción de objeto relacional que significa pensar en totalidades organizadas que se componen de partes heterogéneas en interacción. De esta forma, la organización lleva a pensar en una totalidad relativa, abierta y contextualizada.

Morin entiende que la ciencia moderna se estructuró desde un pensamiento lineal, simple o unidimensional, que disipaba y mutilaba la complejidad de los fenómenos, desde el saber parcelarizado. La ciencia se concibió como disciplinaria, pero la realidad era indisciplinada, 
por tanto, propone tomar partida por el pensamiento complejo, que implica abordar un análisis desde la naturaleza multicausal y multidimensional de un fenómeno, lo que requiere múltiples conocimientos, conectados entre sí y produciendo abordajes y concepciones nuevas. Para recomponer las partes de la realidad fragmentadas por la separación analítica, es necesario promover una mirada simultánea de varias disciplinas. Esta idea fue irrumpiendo lentamente en las estructuras académicas de las ciencias sociales y se ha venido constatando crecientemente la necesidad de superar la parcelación de los enfoques disciplinarios. Los cerrados departamentos e institutos especializados en temáticas o áreas específicas de la realidad social comienzan a mostrar una mayor conexión entre sí y una mayor conformación de equipos interdisciplinarios y multidisciplinarios (Suárez y Sánchez, 2018).

Entonces, desde las ciencias sociales, el pensamiento complejo busca superar la sectorialidad que trae aparejada la especialización y reducir la dicotomía racionalidadrealidad, sujeto-objeto, actor-estructura, público-privado, produciendo un pensamiento no agotado en sí mismo, sino amplio desde la pluralidad de saberes (Veneziano, 2009).

Finalmente, la clásica relación sujeto-objeto se ve cuestionada por la idea de propiedad reflexiva entendida como la capacidad de los sistemas de pensarse a sí mismo, pensar en actos pasados, presentes y futuros, esto fundamenta la idea de relación entre sujetos que se influyen mutuamente (Noboa, 2019).

\section{Las metodologías participativas}

\subsection{Orígenes y desarrollo}

Las nuevas perspectivas teóricas y epistemológicas también tienen un correlato en el desarrollo de metodologías alternativas a los formatos tradicionales de investigación (cuantitativa y cualitativa), así existe un conjunto de aportaciones que fueron surgiendo en diferentes momentos y lugares.

Si bien las primeras investigaciones científicas orientadas a transformar los entornos tuvieron un enfoque funcionalista con los aportes pioneros de Kurt Lewin (1972), quien acuñó el término investigación-acción, sobre todo enfocadas al mundo de las organizaciones, las versiones de la investigación-acción que proponen un verdadero enfoque participativo, y junto con ello una modificación de la relación entre investigadores e investigados, vienen apoyadas sobre todo en los fundamentos del pensamiento crítico desde Marx a la Escuela de Frankfurt (Torres, 2004), y más contemporáneamente autores como Boaventura De Sousa Santos que, con la idea de la ecología de saberes, aporta un sustento importante para el trabajo participativo en la medida que le saca a los expertos el monopolio del saber y permite fundamentar el conocimiento producido en los procesos participativos. 
La teoría crítica desde sus orígenes pone en sospecha los aportes de una ciencia que se pretendía neutra $y$, en esa denuncia, propone una ciencia comprometida con el cambio social. Por esta razón, la investigación no podía quedarse únicamente en la fase de diagnóstico desarrollada en los enfoques clásicos (cuantitativos y cualitativos) y debía incorporar el elemento de la acción transformadora.

Los aportes de la teoría crítica sumados a las condiciones objetivas y subjetivas que vivían países latinoamericanos, como Colombia y Brasil, ambientaron el surgimiento de enfoques como las Pedagogías Populares de Paulo Freire (Brasil) y la Investigación Acción Participativa (IAP) de Orlando Fals Borda (Colombia) (Torres, 2004; Torrejón, 2019).

Como sostiene Noboa (2019), estos enfoques van evolucionando y adquiriendo mayor carga teórica con el paso de los años, así es que aparecen perspectivas como la sociopraxis de Tomás Rodríguez Villasante y la Red Cimas, que desde finales de la década del ochenta del siglo pasado hacen referencia a saltos de la investigación tradicional hacia la complejidad. No son demasiados los trabajos que se abocan a analizar el origen del vínculo entre el pensamiento complejo y las metodologías participativas, en uno de ellos Alejandro Noboa (2019) sostiene que la IAP con el paso del tiempo fue dando un giro e incorporando elementos de la complejidad que no estaban en sus versiones más tempranas. Por su parte, en un texto de la Red Cimas (2020) se sostiene que sobre finales de la década del ochenta Fals Borda declinó de prologarles el libro Las ciudades hablan porque introducía elementos de la complejidad. Sin embargo, sobre principios del siglo XXI, un escrito de Fals Borda reconoce que su trabajo ha sido estimulado por la teoría del caos, los sistemas abiertos, los sistemas de la complejidad, entre otras aportaciones (Noboa, 2019), incluso en una entrevista que le realizó Normando Suárez en julio de 2007 deja clara la sintonía entre la IAP y estas alternativas teóricas. De manera que la hipótesis más plausible es que tanto Fals Borda como sus seguidores fueron paulatinamente encontrando en el pensamiento complejo conceptos que complementaban y fortalecían el fundamento de la IAP.

La perspectiva de complejidad fortalece los fundamentos teóricos de las metodologías participativas y permite organizar mejor los diseños investigativos, incorporando los elementos de autoorganización, reflexividad, no linealidad, la interdisciplina, etc. (Noboa, 2019).

Además de la IAP, las Pedagogías Populares y la Sociopraxis², podemos encontrar desde las últimas décadas del siglo pasado otras aportaciones que también pueden denominarse

\footnotetext{
${ }^{2}$ La Sociopraxis desarrollada por Tomás R. Villasante, Loli Hernández y la Red Cimas es, a nuestro entender, la versión más completa y sistemática dentro de las metodologías participativas. El pensamiento complejo es una referencia explícita en esta metodología e incluye aportaciones metodológicas de movimientos sociales y una variedad de autores como: Guattari, Fals Borda, Luxemburg, Ibáñez, Elias, Galtung, Pichón-Rivière, Chambers, Matus, Freire, Vandana Shiva, B.S. Santos, etc. (Villasante, 2015).
} 
como metodologías participativas como: la Planificación Estratégica Situacional (PES) de Carlos Matus, los Diagnósticos Rurales Participativos (DRP) de Robert Chambers, el Esquema Conceptual, Referencial y Operativo (ECRO) de Enrique Pichón Rivière, entre otros (Suárez y Meneses, 2020).

\subsection{Características}

Estas alternativas metodológicas se nutren de diferentes aportaciones y proponen caminos diferentes, pero coinciden en algunos elementos clave dentro de los que se destacan:

1) El conocimiento está orientado a la transformación social y, por lo tanto, el propio diseño del proceso está pensado no solamente para producir un diagnóstico, sino también para trazar y ejecutar estrategias orientadas a mejorar la situación de las personas. De ahí la idea de investigación-acción. Esto implica que la ciencia no será neutra, sino que tomará partido por aquellos escenarios que representen una mayor justicia social, denunciando las situaciones de injusticia que puedan ser diagnosticadas en los procesos y planificando y desarrollando acciones para producir cambios (Suárez y Meneses, 2020).

2) Además de ser investigación-acción, estas metodologías son participativas. Esto implica que las personas abandonarán su clásico rol de objetos de estudio y se transformarán en sujetos capaces de interpretar las relaciones en las que están inmersos y generar estrategias para cambiar la realidad. La relación pasa a ser sujeto-sujeto. Dicho de otra forma, las personas que participen del proceso, con diferentes niveles de compromiso, asumirán funciones investigativas que tradicionalmente quedaban en manos de expertos (Red Cimas, 2015).

A estos dos elementos centrales se les puede agregar:

3) La idea de que los procesos no son lineales, sino que generan ciclos espiralados o en bucles, lo cual se explica porque cuando se ponen en marcha las líneas de acción se debe evaluar el propio proceso, y monitorear/corregir el mismo. De esta forma, es posible que se produzcan desbordes o paralizaciones de lo planificado, esto lleva a que se comiencen a descubrir nuevos problemas y de esta forma se repite el ciclo (Red Cimas, 2010).

4) Es necesario que se produzca una recuperación histórica, la que se asume como técnica para reconocer y visibilizar la visión del pasado por parte de la comunidad (Torres, 2019). A su vez, este retorno del sujeto permite pasar de grandes narrativas cargadas de certezas a microhistorias locales (Torrejón, 2019).

Las diferentes variantes metodológicas pueden tomar caminos diversos y dentro de una misma metodología hay diferentes posibilidades, dependiendo del contexto y la 
problemática que se aborde. Sin perjuicio de ello, se pueden mencionar algunos elementos generales que es posible encontrar en los diseños participativos.

Para empezar, debe haber una fase inicial en donde se produce la demanda, se conforma el grupo inicial de trabajo (grupo motor, según la terminología de la sociopraxis) y se planifican las primeras ideas para el proceso. Luego, debe desarrollarse un diagnóstico participativo en el cual se deben recoger las diferentes visiones de los actores relacionados al problema. Aquí, asumiendo que no estarán todos participando del proceso, se debe generar una escucha más amplia que incluya a los que no están. Una buena estrategia, propuesta por la Red Cimas (2015), es comenzar con un sociograma que permita identificar a los actores, sus relaciones y sus diferentes posiciones ideológicas frente al problema en cuestión. El mapeo permitirá, entre otras cosas, desarrollar una muestra para mejorar la fase de escucha, en la cual se pueden utilizar diferentes técnicas de investigación social (entrevistas, grupos de discusión, formularios, etc.)

Siguiendo con el diagnóstico, es necesario analizar el material producido y ahí deben involucrarse los participantes del proceso. No se trata de aportar visiones para ser analizadas e interpretadas por expertos, sino de utilizar diferentes técnicas para lograr analizar con los actores y profundizar en el conocimiento de las visiones. En esta etapa, el actor puede fundamentar mejor su visión o puede matizarla en función de otros elementos que van surgiendo en la interacción. El propio análisis puede dar elementos para que los sujetos reflexionen sobre las relaciones en las que están insertos y busquen alternativas para superar las dificultades e impulsar una acción transformadora. Esta visión del participante como investigador que analiza las visiones y los datos que se presentan, y que es capaz de imaginar escenarios estratégicos, se puede fundamentar en los conceptos de reflexividad de las entidades observadas del pensamiento complejo y en la idea de ecología de saberes.

Una vez que se desarrolló el diagnóstico, en donde se debe procurar no producir más conocimiento del necesario para la acción, se debe trabajar en el desarrollo de una planificación participativa orientada a la trasformación de la situación problemática diagnosticada. Las acciones deben implicar, además, la autoorganización de las personas y grupos para asumir roles protagónicos en la ejecución de las mismas. De igual forma, llegado el momento de la ejecución del plan, la actividad debe ser monitoreada por los participantes atendiendo a los posibles cambios en la realidad y a la emergencia de nuevas alternativas; en ese sentido, el esquema debe ser flexible para permitir modificaciones y la emergencia de lo que Villasante (2015) denomina desbordes creativos del plan que mejoran las posibilidades de éxito en el proceso. Luego, es necesario una etapa de evaluación de la ejecución del plan y de esta forma se puede dar lugar a un nuevo escenario para continuar el proceso, asumiendo de esta forma una lógica espiralada que rompe con la idea de la linealidad de los procesos. 


\section{Las metodologías participativas en la construcción de Agendas Municipales de Desarrollo Territorial}

\subsection{Presentación}

Las Agendas Municipales de Desarrollo Territorial (AMDT) son una política impulsada desde la Oficina de Planeamiento y Presupuesto (OPP, primer nivel de gobierno de Uruguay) para ser ejecutada en algunos gobiernos municipales del país (tercer nivel de gobierno).

La política consistió en la elaboración de planificaciones participativas para el desarrollo territorial de las localidades. En ese sentido, se inspira en los marcos de la gobernanza multinivel y el desarrollo territorial. En la etapa de planificación, se contó con apoyo de un equipo técnico, luego de ello, en la etapa de ejecución y monitoreo, continuaron los actores locales (ciudadanos y gobierno) y los técnicos de la OPP.

Así, se desarrolló un proceso participativo durante 2019 enfocándose en tres regiones, en las cuales se elaboraron tres agendas (municipales y microrregiones) en cada una. Este escrito se focaliza en la Región I, que elaboró una agenda microrregional en las localidades de Salto, Belén y Villa Constitución, y dos agendas municipales en Tomás Gomensoro (Artigas) y Tranqueras (Rivera). El motivo por el que se seleccionó la Región I para analizar es porque las agendas que allí se elaboraron contaron con la asesoría técnica de nuestro grupo y eso nos permite conocer el proceso desde adentro y analizar los aspectos positivos y negativos dentro del proceso, así como extraer aprendizajes de la propia práctica.

\subsection{Fundamentación}

Para explicar el fundamento de la política aplicada en el ámbito municipal, se debe tener en cuenta que el Uruguay pone en marcha el nivel de gobierno municipal en 2010, actualizando al país en relación con los gobiernos democráticos de la región y continuando con una transformación del Estado iniciada en 2005 bajo los pilares de modernización y fortalecimiento institucional (Narbondo et al., 2010) y acercamiento a la ciudadanía (Cardarello et. Al., 2010). En su gran mayoría, los municipios están asentados sobre poblaciones pequeñas (entre 2000 y 20000 personas) en el interior de los departamentos.

Desde la OPP, perteneciente a Presidencia de la República, se han creado programas orientados a acompañar este proceso de descentralización. En ese sentido, las Agendas Municipales de Desarrollo Territorial (AMDT) son parte de una estrategia impulsada desde el gobierno central uruguayo para dotar al nivel municipal de mecanismos concretos de 
relacionamiento con la ciudadanía. Además de este aspecto apoyado en la perspectiva teórica de la gobernanza, las AMDT apuntan a contribuir al desarrollo de la localidad desde la perspectiva del desarrollo territorial, el cual es concebido como un proceso que busca lograr mejoras en las condiciones de vida de la gente que vive en un determinado ámbito territorial y para ello es necesario un abordaje integral de los problemas y una participación activa de los actores locales (sociales y empresariales) que trabajan de manera articulada con el gobierno local (Alburquerque, 2013).

Desde la perspectiva del desarrollo territorial, se puede decir que la construcción de las agendas apunta a la construcción de una visión compartida y estratégica entre los actores territoriales sobre el futuro de la localidad (OPP, 2019). Si bien hay un énfasis en el elemento productivo como elemento central en el desarrollo, y por ello se parte de un perfil socioproductivo de las localidades, las AMDT no se han quedado en ello y han apuntado a una mirada integral del fenómeno, trabajando también sobre aspectos sociales, ambientales, institucionales, etc.

\subsection{Características del proceso}

En primer lugar, la OPP hace un llamado a municipios interesados en desarrollar un proceso participativo para planificar el desarrollo territorial. Como se dijo, la problemática que motiva el llamado tiene que ver tanto con la existencia de territorios que necesitan una estrategia de desarrollo como con la necesidad de dotar a los municipios de herramientas concretas de relacionamiento con los actores locales.

Sus objetivos son:

Objetivo general: fortalecer las capacidades de planificación y gestión de los municipios, con participación ciudadana y coordinación interinstitucional.

Objetivo específico 1: diseñar e implementar metodologías que promuevan instancias participativas orientadas a la planificación territorial.

Objetivo específico 2: definir lineamientos estratégicos e identificar acciones para su promoción e implementación en el corto y mediano plazo (OPP, 2019).

Si analizamos los objetivos de la política a la luz de los postulados de la teoría crítica y de la complejidad, podemos ver que la misma intenta romper con los supuestos positivistas reflejados en la planificación normativa. En este caso, se busca planificar con los actores locales, asumiendo que el conocimiento experto no es el único válido y buscando a su vez implementar acciones para el cambio que involucren diferentes horizontes temporales. Las ideas de participación ciudadana y coordinación interinstitucional presente en los objetivos, sumadas a la coordinación entre niveles de gobierno que está en el seno de la propia política, tienen una fuerte conexión con los postulados del pensamiento complejo, en especial con la premisa de que la complejidad de la realidad es multicausal, 
multidimensional y multifactorial, por lo que la superación de los problemas trasciende tanto la exclusividad estatal como la especialización sectorial y requiere intervenciones públicas integrales. La perspectiva de la complejidad se ha cristalizado en conceptos como transversalidad, coordinación intersectorial, gobierno multinivel, cooperación entre lo público estatal, lo privado y lo público no estatal. Las AMDT, buscando promover un desarrollo territorial que es por definición multidimensional y multisectorial, y poniendo en conexión para ello a los diferentes niveles de gobierno entre sí y con la ciudadanía, encuentran buenos fundamentos en el pensamiento complejo.

Más allá de la estructura básica diseñada por la OPP, cada grupo técnico propuso para cada región una metodología propia.

A nivel general, las AMDT se organizaron sobre la base de las siguientes etapas:

1. Invitación a los municipios a participar: se realiza un llamado abierto a todos los municipios del país que tengan interés en participar de la experiencia.

2. Selección de municipios: la OPP a través de la Dirección de Descentralización e Inversión Pública realizó una selección basándose en la potencialidad del municipio para llevar adelante un proceso de planificación participativa y el sentido de oportunidad y viabilidad política e institucional.

3. Llamado a licitación de equipos técnicos: se seleccionó un equipo técnico para cada una de las tres regiones.

4. Proceso participativo de elaboración de la agenda.

En el caso de la Región I, se partió de una reunión inicial con alcaldes y concejales como grupo que impulsó el proceso a nivel local. Con ellos se realizaron los acuerdos sobre las características que debería tener el proceso y los roles que cada cual debía asumir. Luego se realizó una primera aproximación a un mapa de actores, con el fin de poder realizar un trabajo de escucha a través de entrevistas cualitativas.

Por las características de la reunión, solamente con el alcalde y algunos concejales, este primer mapeo fue más bien un listado de actores pertenecientes a diferentes rubros de la sociedad local, educativos, salud, productivos, políticos, etc., con el objetivo de desarrollar la muestra cualitativa.

Luego de ello, los técnicos realizaron el trabajo de campo cualitativo que fue uno de los insumos para la elaboración de un perfil socioproductivo de la localidad. La muestra se realizó utilizando el listado de actores de la primera reunión, pero también aplicando la técnica bola de nieve para garantizar cierta pluralidad de voces. Las entrevistas buscaban las percepciones sobre los principales sectores productivos, sus fortalezas, oportunidades, debilidades y amenazas, sobre los sectores que generaban más empleo, sobre las potencialidades del municipio para generar una agenda de desarrollo territorial y algunas propuestas en ese sentido. Este producto sirvió para el desarrollo de un documento de perfil 
socioproductivo que se nutrió además de datos secundarios existentes y estudios previos. El producto después fue socializado con los participantes en el primer taller en donde se discutieron y profundizaron los diferentes contenidos. Es interesante destacar que aunque sea focalizado en el elemento socioproductivo, se logró recoger una diversidad de voces en favor y en contra de la planificación que inmediatamente fue llevada para discutir con los participantes. De esta forma, el proceso logró contemplar y analizar las opiniones de algunos actores clave que posteriormente no participaron del proceso.

La instancia participativa consistió en cinco reuniones con una convocatoria abierta en la cual participaron actores del ámbito político, social y económico.

La propuesta participativa para la construcción de las agendas territoriales comenzó con una etapa de diagnóstico participativo en donde se pusieron en juego diferentes técnicas de mapeo (de actores y recursos) dinamizadas con la lógica del Café Mundial. Con ello, se buscó relevar desde la percepción de los participantes cuáles eran las características de la localidad en relación con los diferentes recursos con los que cuentan, los actores relevantes del territorio y las debilidades y fortalezas con respecto a la puesta en marcha de las agendas de desarrollo territorial. Fue en esta etapa, que consistió en dos talleres de tres horas, en donde se discutió y profundizó el perfil socioproductivo elaborado anteriormente. Además, se generaron insumos para la planificación de la instancia de diagnóstico participativo que tiene un valor en sí mismo, como es mencionado por el pensamiento crítico, y que genera procesos autorreflexivos que permiten a los participantes comprender la complejidad de los fenómenos, así como las dificultades estructurales de los territorios, cosa que en estos casos tenía mucho sentido por tratarse de pequeños territorios muy alejados de la capital de un país centralista. Los procesos deliberativos funcionaron como procesos de aprendizaje y posibilitaron transformaciones en los propios sujetos.

Luego, se llevó a cabo la etapa de planificación, en la cual, considerando el diagnóstico y los marcos de desarrollo territorial a escala departamental, nacional e internacional, se definieron líneas estratégicas, objetivos y acciones para cada línea. También se conformó una comisión de seguimiento de la agenda. Esta instancia puso en diálogo elementos del saber experto con los del conocimiento cotidiano, ya que, por un lado, los técnicos, siguiendo las recomendaciones de la OPP, presentaron otras planificaciones presentes a una escala mayor, recomendando tenerlos en cuenta a la hora de planificar como forma de potenciar el argumento de lo planificado a escala local y como forma de acumular esfuerzos. Sin embargo, fueron los propios participantes quienes definieron prioridades y maneras de abordar los problemas. También en esta línea de diálogo y de saberes, por otro lado, se fomentó la idea de buscar información de un taller para otro, de manera de tomar decisiones con la mayor información posible. 
Finalmente, se realizó una jornada de validación en la cual se presentó a los participantes el borrador de la agenda y se recibieron retroalimentaciones con miras al desarrollo del producto final. Aquí se debe decir que, desde las perspectivas críticas, se maneja la idea de coescribir con los propios actores, pero en este caso se trabajó a un nivel diferente, en donde la escritura estuvo en manos de técnicos, pero sometida a la corrección de los actores. Para ello, se compartió el texto borrador por correo electrónico y luego se realizó una instancia de discusión. La opción de que la redacción la liderara el equipo técnico tiene que ver con la necesidad de cumplir con los acotados tiempos marcados por la administración central.

Lo trabajado en cada taller se puede sintetizar así:

Taller 1: construcción de un concepto compartido de desarrollo territorial (lluvia de ideas), presentación y discusión del perfil socioproductivo de la localidad y mapeo de recursos y actores (café mundial).

Taller 2: identificación de los principales problemas para el desarrollo, así como desafíos y potencialidades para el abordaje. Como paso previo a la planificación, se presentaron a los participantes planes y acciones de desarrollo departamental, regional, nacional e internacional que podían servir como marco para la agenda.

Taller 3: definir y priorizar líneas estratégicas. Formular objetivos para las líneas priorizadas. Buscar articulaciones entre las líneas priorizadas y los planes de desarrollo trabajados en el taller dos.

Taller 4: planificar acciones para las diferentes líneas estratégicas (técnica de las 9 cuestiones). Selección de una comisión de seguimiento de la agenda.

Taller 5: validación de la planificación y desarrollo de indicadores para el monitoreo.

\subsection{Actores y roles}

Participaron representantes de instituciones educativas, emprendedores y empresarios locales, gobernantes locales (alcaldes y concejales), entre otros actores.

Los gobernantes locales fueron los anfitriones, coordinaron junto con la Oficina de Planeamiento y Presupuesto y el equipo de técnicos el cronograma de reuniones, etc. Ellos proporcionaron el lugar de reuniones y algunos recursos necesarios para el trabajo. Además de ello, tomaron el rol de participantes activos trabajando juntos con la ciudadanía en el armado del diagnóstico y del plan.

El equipo técnico estaba compuesto por dos integrantes del equipo consultor que proponían las dinámicas, moderaban las discusiones, procesaban los materiales producidos en las reuniones y luego los devolvían en talleres siguientes para profundizar en el análisis 
junto con los participantes y para corregir eventuales errores interpretativos. El equipo técnico de la consultoría trabajaba de manera coordinada con dos referentes territoriales de la OPP (uno del programa Uruguay Integra y otro del programa Uruguay Más Cerca) que acompañaban el proceso buscando generar una buena articulación con los diferentes actores. Finalmente, los ciudadanos participantes tuvieron un rol protagónico en los talleres, en donde se elaboró el diagnóstico y el plan, a su vez, en el mismo, se previó que en la ejecución y el monitoreo estuvieran presentes grupos de ciudadanos distribuidos en equipos operativos según sus intereses. La idea de autoorganización de los sistemas está claramente presente aquí, pero está basada en la premisa de que en una primera instancia es conveniente que los técnicos externos ejerzan la coordinación mientras se van generando los lazos de confianza y tejiendo los vínculos de la red local. En una segunda instancia, que comienza en la fase de ejecución y monitoreo, se buscaba que ese sistema de actores locales pudiera funcionar como un esquema autoorganizado, este es uno de los principales desafíos que la política deja planteado en los territorios.

\subsection{Resultados}

Las agendas se encuentran actualmente en fase de ejecución, no se dispone de información sobre el nivel de ejecución, por lo que la referencia aquí será sobre los resultados del proceso participativo hasta la construcción de las agendas. En la Región I, luego de finalizado el proceso de planificación participativa, se obtuvo como resultado dos agendas municipales y una microrregional. En total participaron 104 personas de algunas de las 15 instancias realizadas para elaborar las tres agendas, 11 de ellas participaron de los 5 talleres. En detalle: 48 vecinos o de organizaciones sociales/culturales, 39 personas del sector público, 23 de municipios, 17 personas del sector privado (OPP, 2019).

Las agendas elaboradas, además de un diagnóstico y perfil socioproductivo de la localidad, contienen una planificación con objetivos generales, ejes temáticos con objetivos específicos, acciones para llevar adelante las mismas (detallando el cronograma, los actores responsables, recursos necesarios, etc.) y un sistema de monitoreo. En general, todas las agendas de la región trabajaron intentando potenciar el desarrollo económico a través del fomento de determinados sectores productivos como forma de generar mayor empleo. Se desprende, a su vez, tanto de los diagnósticos como de las acciones propuestas, una preferencia por la multiplicidad de inversiones vinculadas a los rubros que la búsqueda de una gran inversión para la zona. Esto marca un enfoque del desarrollo orientado a dar un protagonismo a los actores locales. Hubo también agendas como la de Tranqueras o la de Tomás Gomensoro, en donde la propuesta trascendió por el elemento productivo, generando ejes y acciones vinculados a aspectos sociales y culturales con una preocupación en ambos casos por las actividades juveniles. Es interesante destacar en el caso de Tomás 
Gomensoro la preocupación por el estado del ambiente y la necesidad de compatibilizar la actividad productiva con el cuidado del mismo (un enfoque sustentable).

Ejes trabajados:

Belén-Villa Constitución: 1) Turismo natural y cultural, 2) Horticultura asociativa y de calidad.

Tranqueras: 1) Turismo, 2) Producción rural y familiar, 3) Forestación y madera y 4) Cultura.

Tomás Gomensoro: 1) Medio ambiente, 2) Trabajo, 3) Actividades sociales y culturales y 4) Servicios sociales (salud, educación).

Por último, se puede decir que se espera que estas agendas consoliden algunos espacios y grupos de trabajo comunitario que apoyen la tarea de los municipios y puedan ser generadores de debates y aportes al desarrollo de las comunidades, validando de alguna manera el trabajo generado entre todos.

\subsection{Aprendizajes y desafíos}

La aplicación de metodologías participativas para la planificación en espacios institucionalizados tiene la ventaja de potenciar los procesos de participación ciudadana en la medida que posibilita a los participantes, a través de las metodologías, levantar la mirada de los problemas particulares y pensar en la comunidad en su conjunto y cuáles son los problemas y deseos más sentidos. En estos casos, la presencia de los alcaldes o alcaldesas en todos los talleres se observó como un aspecto clave que dio respaldo al proceso, al tiempo que permitió resolver muchos aspectos operativos y contar con información valiosa para la toma de decisiones. En ninguno de los casos se observó un intento de los actores políticos por controlar el proceso participativo e incorporar en la agenda aspectos que tenían interés para ellos y sus partidos.

Otro desafío importante, vinculado a la institucionalización, es que las AMDT son promovidas tanto desde el gobierno central como desde el gobierno municipal $y$, en ese sentido, la proximidad de las elecciones al momento de planificar presenta el desafío de la continuidad en caso de cambio de autoridades. Este desafío está presente en todos los procesos de este tipo, pero se puede minimizar si la planificación se inicia al principio y no al final de los periodos quinquenales de gobierno.

Otro aspecto desafiante es que es necesario adaptar el proceso a las exigencias de la administración que en general están ya estipuladas en los pliegues licitatorios. Una de las adaptaciones principales es la necesidad de comprimir el proceso participativo, lo que implica talleres un tanto largos y cargados de actividades, y, por otro lado, quita posibilidades para que emerjan más ideas creativas. Vinculado a este problema de plazos, en los tres procesos se terminó con un sistema de monitoreo que no pudo trabajarse en 
profundidad con los actores y eso podría generar dificultades en la implementación. Los procesos no institucionalizados suelen ser muchos más flexibles con los tiempos y van trabajando sobre la marcha en virtud de los ritmos de la propia población.

Otro aspecto vinculado a las reglas institucionalizadas que se visualizó como negativo en el proceso es que se estipuló que, luego de la fase de planificación participativa, el equipo técnico contratado se retira, y en la fase de ejecución y monitoreo los actores locales (gobierno y ciudadanos) continúan solos con el proceso. Si bien esto está contemplado en la planificación, en donde se deben generar grupos operativos tanto para la ejecución de las acciones como para el monitoreo del plan, es un desafío para la comunidad local que, en general, no está acostumbrada a estos esquemas autoorganizativos y que venía trabajando bajo la coordinación de los técnicos. Tal vez se podría haber implementado una retirada más gradual del equipo técnico, posibilitando un acompañamiento en el inicio de la fase de ejecución y monitoreo. De esta forma, se podría asegurar la continuidad del proceso y se evitaría las entradas y salidas abruptas de técnicos en el territorio.

Uno de los aprendizajes que se extrajeron fue que cuando se trata de llamados para pensar y planificar temas abstractos como el desarrollo de la localidad, no basta con difundir por diferentes medios y enviar cartas de invitaciones a ciertos actores clave, sino que es necesario comprometer de ante mano la colaboración de algunos de ellos. En ese sentido, en Tomás Gomensoro se tuvo que suspender el primer taller y volverlo a realizar porque asistieron muy pocas personas para llevarlo a cabo. Luego, la asistencia mejoró debido a que el alcalde y un concejal definieron como estrategia hablar personalmente con diferentes actores y aseguraron un número básico de asistentes que se pudo mejorar con la convocatoria general. También vinculado a la convocatoria y teniendo en cuenta la escasa presencia de adolescentes jóvenes en los tres procesos, se puede decir que en experiencias futuras podría ser interesante implementar espacios de participación juvenil, con una convocatoria y modalidad específica, que articulen con los espacios generales.

\section{Conclusiones}

Las metodologías participativas son una alternativa a los modelos clásicos de investigación en donde no solo se incorpora la idea de acción, y con ello se le da a la tarea un poder transformador, sino que se trasforman los roles, pasando de una relación sujetoobjeto a una de relación entre sujetos. La primera investigación-acción no es aún participativa y este componente se comienza a desarrollar en América Latina a fines de los sesenta y principios de los setenta, con los aportes de Freire y Fals Borda. Una de las aportaciones clave ha sido la Investigación Acción Participativa (IAP) que ancla sus raíces sobre todo en el pensamiento crítico. Hoy existe una gran variedad metodológica que 
comparten algunos principios epistemológicos y metodológicos básicos que hacen que en su conjunto se pueda hablar de metodologías participativas. Uno de los desarrollos contemporáneos más completos viene de la mano de Tomás Villasante y la Red Cimas, con la variante que ellos denominan sociopraxis y que bebe de una gran variedad de corrientes teóricas, entre ellas, las teorías de la complejidad.

El artículo, además de mostrar las bases teóricas y los principios epistemológicos y metodológicos de las metodologías participativas, describió y analizó la utilización de las mismas en un proceso participativo orientado a la construcción de agendas de desarrollo territorial en municipios uruguayos. Se extrajeron algunos aprendizajes que podrían dar pistas para mejorar los procesos en el ámbito de las políticas públicas.

Por un lado, la cercanía con las elecciones y los posibles cambios de autoridades es siempre un desafío a estas planificaciones que incorporan elementos de mediano y largo plazo, en ese sentido, la recomendación sería comenzar estos procesos más cercanos al inicio que al final de los periodos de gobierno. De esta forma, el gobierno que los promueve puede garantizar el avance del plan por varios años.

Se valora como positiva la presencia de las autoridades locales en los talleres porque le da respaldo al proceso y en estos casos, en donde el gobierno local debe asumir un rol clave en la coordinación de la ejecución, es fundamental que la gente perciba que existe un respaldo institucional. El riesgo estaría en que los gobernantes busquen incidir en las definiciones ciudadanas; en los casos analizados no se visualizó este problema.

Los tiempos de desarrollo de la fase de diagnóstico y planificación son un desafío importante en estos procesos, las propias bases definidas por la administración tienden a estipular procesos relativamente cortos, como sucedió con las AMDT, y eso lleva a que se planteen talleres largos, muy cargados de técnicas y aun así no se logre trabajar en todos los casos con un buen nivel de precisión y discutiendo lo suficiente las ideas como para que emerjan todas las visiones alternativas y las opciones más creativas. Una posibilidad a explorar sería combinar estos trabajos de talleres presenciales con algunos encuentros virtuales que podrían ser con grupos específicos por temáticas, que pudieran realizar avances para nutrir los talleres presenciales. Este proceso participativo se desarrolló antes de la pandemia y en ese sentido solamente contempló talleres presenciales, pero hoy los avances en materia de participación digital llevan a pensar que es posible mejorar el aspecto de la falta de tiempo en los talleres combinando los formatos (presencial-virtual).

Otro aspecto a señalar es que cuando se aplican metodologías participativas en la esfera pública no es la primera vez que se ve que el acompañamiento técnico culmina cuando se ha elaborado el plan. Esto, por un lado, provoca un desacople con el resto del proceso que hace que se pierda la visión del proceso como conjunto, y por otro, pone en riesgo el éxito del proceso como mecanismo transformador. 
Para finalizar, cabe reflexionar sobre el carácter disruptivo de la herramienta. En ese sentido, hay algunas conclusiones que se pueden extraer del análisis realizado y otras que requieren de investigaciones futuras. En primer lugar, la propuesta de planificar el desarrollo desde lo local, y poniendo en diálogo los saberes cotidianos, los conocimientos técnicos y las lógicas políticas, es una práctica que rompe con los postulados positivistas expresados en la planificación normativa. Acá la apuesta es pensar el desarrollo de manera no lineal y contextualizado. Esta fue, para varios gobiernos municipales, la primera experiencia en su poco tiempo de existencia en la que realizan un trabajo de planificación colaborativa y conforman una red de trabajo con los actores locales.

Por otro lado, la herramienta de AMDT es concebida desde el gobierno $y$, en ese sentido, no solo debe incorporar las reglas de la institucionalización que no necesariamente se armonizan con las principios metodológicos de la investigación participativa, sino que además, al surgir como propuesta del propio centro de poder político, es difícil imaginar que se transforme en una herramienta contrahegemónica o capaz de alterar sustantivamente las lógicas de poder. Sin embargo, hay algunos aspectos interesantes que potencian su capacidad de transformar el territorio desde lo local. Por un lado, el hecho de que la agenda no esté sujeta a una aprobación inmediata de fondos económicos para su financiación lleva a que lo planificado no pase por filtros ni esté sujeto a lineamientos externos durante la planificación. Por otro lado, los actores sociales, políticos y empresariales han tendido a identificarse sobre todo como parte de una localidad del interior que sufre las consecuencias del centralismo político y así las agendas tendieron a percibirse como herramientas para luchar contra el centralismo y para generar condiciones para vivir una vida digna en los lugares más alejados de los centros de poder.

Se puede decir que luego de finalizada la fase de planificación, tanto los ciudadanos participantes como los gobiernos ganaron en su capacidad de entender la complejidad de la trama local y sus vinculaciones con los escenarios departamentales, nacionales y globales. También es posible afirmar que los gobiernos locales culminaron la fase de planificación con una red de actores locales en la que pueden apoyarse para gobernar participativamente si así lo desean. Sin embargo, no es posible todavía dar una respuesta sobre qué le dejaron estos procesos a los territorios. Para ello, queda pendiente analizar el logro de los objetivos planteados en las agendas y los efectos que la pandemia generó sobre la fase de ejecución. Este aspecto es importante porque, pese a los logros obtenidos en la fase de planificación, mejorar la situación de los problemas diagnosticados depende del desarrollo exitoso de las acciones planificadas y si no se logra avanzar en esto, el proceso irá perdiendo legitimidad y debilitando los vínculos generados. Este aspecto queda como agenda de investigación futura, para seguir conociendo sobre el poder transformador de la herramienta. 


\section{Referencias bibliográficas}

Alburquerque, F. (2013). Economía del desarrollo y desarrollo territorial. Programa ConectaDEL.

Alvarado, L. y García, M. (2008). Características más relevantes del paradigma sociocrítico: su aplicación en investigaciones de educación ambiental y de enseñanza de las ciencias realizadas en el Doctorado de Educación del Instituto Pedagógico de Caracas. Revista Universitaria de Investigación, Año 9, 2.

Cardarello, A.; Freigedo, M. y Vairo, D. (2010). Mucho ruido... y algunas nueces. Los vaivenes de la descentralización en la administración Vázquez (2005-2010). En Narbondo, P. y Mancebo, M.E. (coords) Reforma del estado y políticas públicas en la Administración Vázquez: acumulaciones, conflictos y desafíos. Montevideo: Clacso-ICP-Editorial Fin de Siglo.

Fals Borda, O.; Brandao, C. y Cetrulo, R. (1991). Investigación participativa. Montevideo: Ed. Banda Oriental.

Habermas, J. (1994). La teoría de la acción comunicativa, complementos y estudios previos. Madrid: Cátedra.

Lewin, K. (1972). Psichologie Dynamique. Paris: PUF.

Melero, N. (2011). Un análisis desde las ciencias sociales. Cuestiones Pedagógicas, 21, 2011/2012, 339-355.

Morin, E. (2007). Introducción al pensamiento complejo. España: Gedisa.

Narbondo, P.; Fuentes, G. y Rumeau, D. (2010). La reforma de la administración central: marchas, contramarchas y bloqueos. En Narbondo, P. y Mancebo, M.E. (coords) Reforma del estado y políticas públicas en la Administración Vázquez: acumulaciones, conflictos y desafíos. Montevideo: Clacso-ICP-Editorial Fin de Siglo.

Noboa, A. (2019). Caminos de confluencias entre el pensamiento complejo y la Investigación Acción Participativa en Latinoamérica. Revista Latinoamericana de Metodología de la Investigación Social, Año 9, 17, 50-68.

Noboa, A. y Suárez, M. (2018). Conexiones entre teoría crítica, complejidad y metodologías participativas de la investigación social. Espacio abierto (Caracas. 1992), (27)2,121-132.

OPP (2019). Agendas Municipales de Desarrollo Territorial. Serie Síntesis Metodológica. Montevideo: Autor.

Popkewitz, T. (1988). Paradigma e ideología en investigación educativa. Las funciones sociales del intelectual. Madrid: Mondadori.

Red CIMAS (2010). Metodologías participativas. Manual. Madrid: Autor. (2015). Metodologías participativas. Sociopraxis para la creatividad social. Madrid: Ed Dextra. 
(2020). Estrategias transformadoras: cómo potenciar la creatividad colaborativa desde los movimientos y procesos sociales. Madrid: CIMAS.

Sánchez Santamaría, J. (2013). Paradigmas de investigación educativa: De las leyes subyacentes a la modernidad reflexiva. Revista Entelequia, 16, 91-102.

Suárez, M. y Meneses, F. (2019). Metodologías participativas: Orígenes y características del proceso. En Noboa, A. (coord.) Conocer lo Social III. Las metodologías emergentes. Salto: Fundación de Cultura Universitaria.

Torrejón, E. (2019). De la disidencia a la convergencia: métodos emergentes en la Investigación Social. En Noboa, A. (coord.) Conocer lo Social III. Las metodologías emergentes. Salto: Fundación de Cultura Universitaria.

Torres, A. (2004). Por una investigación desde el margen. En Jiménez Becerra, A. y Torres Carrillo, A. (comp.) La práctica investigativa en ciencias sociales. Bogotá: UPN.

Veneziano, A. (2009). Descentralización, desarrollo local, participación ciudadana y reforma del Estado: Una vinculación pendiente. Montevideo: Ediciones ORBE.

Villasante, T. (2015). Prólogo. En Suárez, M. (comp.) Pensar la Democracia Participativa. Salto: Fundación de Cultura Universitaria. 